\title{
Electronic dreaming tracks: indigenous community broadcasting in Australia
}

\author{
Michael Meadows
}

A wide range of audiences now accesses indigenous community radio and television across Australia. This article draws from the first-ever audience study of the sector, 'Community Media Matters', completed in 2007. It reveals that Aboriginal and Torres Strait Islander media offer an essential service to communities and play a central organising role in community life. Although previous studies into the Australian indigenous media sector have suggested this, it is the first time that audiences from the cities to the most remote parts of the continent have had a chance to confirm the importance of locally produced media in their lives. This has revealed new insights into the nature of the relationship between audiences and the producers of indigenous community radio and television.

Key Words: Oceania and Japan; Technology; Governance and Public Policy

\section{Introduction}

Aboriginal social organisation is bound up in the notion of 'the Dreaming', which might be interpreted as referring to the law and a relationship to time and space in which ancestral beings' journeys across the landscape shaped natural features and described 'Dreaming tracks'. These pathways can also be considered to be information conduits or media, along which information and people travel, carrying goods for exchange and moving between ceremonial sites (Michaels 1986: 508). Following the return of their ancestral lands in 1985, the Anangu (Pitjantjatjara) now co-manage the Uluru-Kata Tjuta National Park (Ayers Rock-Mount Olga) in central Australia. They use the term Tjukurpa to help explain their interpretation of 'the Dreaming', incorporating religious heritage and the relationship between people, plants, animals, and physical features in the landscape. This term represents not only the law and rules of everyday behaviour, but also ideas concerning the past, the present, and the future. But importantly, they remind us, 'The Tjukurpa is not a dream; it is real' (Australian National Parks and Wildlife Service and Mutitjulu Community 1990). And it is only indigenous media that have been able to 'reflect the real' in terms of the everyday lives of Australia's population of Aboriginal and Torres Strait Islander people. 
The power and influence of mainstream media continues to transform the wider public sphere, compelling indigenous people to seek access to their own media for political, educational, and cultural reasons. This global trend has been influenced by the recognition of the potential for using media as tools for cultural and political intervention - effectively, allowing the dispossessed the capacity to speak as well as hear their own stories. This process has been driven by several impulses: combating stereotypes, addressing information gaps in non-indigenous society, and reinforcing local community languages and cultures.

While in one sense this activity is at the periphery of mainstream conceptions of the public sphere, I will argue here that the implications are far more profound. Rather than adopting the idea of a single, all-encompassing public sphere, we should think in terms of a series of the existence of parallel and overlapping public spheres - spaces where participants with similar cultural backgrounds engage in activities of importance to them. Each of us simultaneously has membership of several different public spheres, moving between and within them according to desire and obligation. In this way, these multiple spheres of activity articulate their own discursive styles and formulate their own positions on issues that are then brought to a wider public sphere where they are able to interact ‘across lines of cultural diversity’ (Fraser 1993: 13; Avison and Meadows 2000).

Behind much of the impetus for the development of indigenous media production globally is the fear of further cultural and language loss because of the influence of mainstream media. For most indigenous people, Western-style media represent a double-edged sword - both a threat and a promise. Although sometimes identified as purveyors of cultural imperialism, media technologies and media practices have the potential to be powerful community cultural resources to enable activity in the public sphere. Such alternative media practices extend contemporary ideas of the public sphere and democracy. And there is considerable evidence to suggest that indigenous media producers have appropriated various media technologies to suit their own social and cultural needs. The foundation of this is functionality - that there must be a clear benefit flowing from the adoption of technologies of any kind. This is especially the case in remote indigenous communities, which are commonly required to confront 
issues of survival on a daily basis. I'm suggesting here that indigenous media production - or ‘invention’ as Eric Michaels (1986) describes it - has contributed to a reconceptualising of the notion of the public sphere.

A key influence on the quest by indigenous people for media empowerment is a continuing failure by the broader public sphere to account for indigenous cultural needs. This has played a central role in the development of alternative media systems primarily non-profit, volunteer-run, community-based radio and television stations and, as a result, alternative public spheres, including indigenous public spheres. Audience reception has powerful political and cultural implications, so it should not be surprising to find that indigenous audiences have responded in this way. At the same time as indigenous voices remain suppressed in mainstream news coverage of events in which they are deeply implicated, indigenous agency has been a crucial element of a global push for media access. Gail Valaskakis (1993) echoes the experiences of many indigenous peoples when she concludes:

Today, we are all caught in a web of conflicting interests and actions, confrontations constructed in dominant cultural and political process and the Native experience of exclusion, or stereotypical inclusion and appropriation. For people of the First Nations, this involves the subaltern experience rooted in the lived reality and the representation of the 'insider', the 'outsider', and the 'other'.

She has coined the term 'parallel voices' to illustrate the idea of separate universes inhabited by indigenous and non-indigenous peoples sharing virtually the same spaces. The extraordinary differences between indigenous and non-indigenous media in form and content is further evidence for their existence.

In this paper, I want to canvass some of the ideas around indigenous media that have begun to coalesce following the most recent audience research in Australia. The study included extended visits to 14 regions and cities around Australia, culminating in around 150 interviews with listeners to and viewers of indigenous community radio and television programmes (Meadows et al. 2007). The findings offer greater understanding of not only the sector itself and its empowering potential, but also of the dominant 
media processes that are central to the formation and sustainability of the broader democratic public sphere.

\section{Indigenous radio and television}

The community broadcasting sector has proved to be a major communications outlet for indigenous voices in Australia. The term 'community' in this discussion refers to local, non-profit radio and television licences operated by a diverse range of 'communities of interest' around the country. Most stations have a handful of paid employees, funded from local business or government sponsorship of programmes. The entire community broadcasting sector in Australia has an annual turnover of around AU\$50 million (€24 million). At the end of 2007, there were around 450 licensed community broadcasters operating in urban, regional, and remote Australia. Indigenous community stations tend to be run by a handful of paid workers indigenous and non-indigenous - supplemented by volunteers and others from local communities receiving unemployment benefits. Funding for the indigenous community broadcasting sector comes from the federal government with around AU\$14 million (€6.8 million) allocated to the indigenous sector in 2007. Around 105 licensed community radio stations in remote regions broadcast more than 1000 hours of indigenous content weekly, with a further 25 stations operating in regional and urban areas. There is one indigenous commercial radio station, 6LN in Carnarvon in Western Australia, and one commercial television station, Imparja, based in Alice Springs in central Australia. Aboriginal and Torres Strait Islander people have won access to the airwaves following persistent campaigns. Most major urban and regional areas have an indigenous broadcaster complementing existing media. In addition to the community stations, there are two indigenous radio networks. The satellitenetworked National Indigenous Radio Service (NIRS) was launched in 1996 enabling indigenous community radio stations across Australia to either link into national programming or choose to broadcast locally. In 2001, the National Indigenous News Service (NINS) began operating out of the NIRS studios in Brisbane, providing a general, independent, national news service that features indigenous stories and indigenous perspectives on general news (Molnar and Meadows 2001).

At the beginning of 2007, there were 96 stations broadcasting indigenous programming across Australia and an additional 80 Remote Indigenous Broadcasting 
Services (RIBS) serving communities in the most remote parts of the continent. Most of the small, remote stations are engaged in retransmitting available satellite programming, both mainstream and community produced. When it started in 1988, Imparja Television was the world's first Aboriginal-owned commercial television station. Largely for financial reasons, Imparja is able to produce only a few hours of indigenous content a week. However, an Aboriginal owned and run Indigenous Community Television service (ICTV) began broadcasting from one of Imparja's spare satellite channels in 2001. This innovative service features close to 100 per cent indigenous content, produced mostly by small bush communities and often in local or regional languages. ICTV reaches an increasing number of regional and remote communities with the facility to downlink the satellite signal. It was initiated by the Aboriginal-controlled PY Media, producing around 300 hours of new content annually since 2005. The service, coordinated until recently by PY Media, ran on an annual budget of about AU\$70,000 (€34,000) and included contributions from Remote Indigenous Broadcasting Service (RIBS) community hubs, including PY Media, Warlpiri Media, Pilbara and Kimberley Aboriginal Media (PAKAM), Ngaanyatjarra Media, and TEABBA. Until October 2006, when ICTV was incorporated as a separate organisation, PY Media coordinated 20 hours a day of indigenous community TV programming. The 20 hour block, which repeated daily, was replaced with new programming material each month.

Towards the end of 2006, the federal government committed AU\$48 million (€23.4 million) over four years to develop a National Indigenous Television Service. This was launched on 13 July 2007. As a result, there was great concern by a number of bush communities that 'their' television service would be compromised. At the time of writing, the relationship between the existing ICTV service and the proposed NITV service remained unclear, although the ‘bush’ communities have been able to negotiate access to the national channel for a selection of their community-produced programmes to be broadcast.

\section{Interrogating the audience-producer dialogue}

One of the dominant defining characteristics of indigenous audiences that has emerged from the research is the absence of a barrier between audiences and 
producers of indigenous media. One media worker at Yuendumu in the Tanami Desert in central Australia described it like this:

The audience are the producers and we get constant feedback from them as to what they want and also that they're prepared to just get up there and do it themselves and the separation of production processes from audience - it's a unique situation; it's something that the government should treasure.

But in the locations we visited as part of this study, audiences expressed this in different ways: a sense of ownership, communication, identification with the 'grassroots', access, and the innate ability for stations to relate to their listeners socially, culturally, and linguistically. One listener said simply: 'I feel more comfortable than when I hear any white man's radio station. Absolutely more comfortable.' Another interviewee from Palm Island, off the far north Queensland coast, observed:

It certainly arouses people when they can hear something that belongs to us; that's about us. It's a very special tool to Aboriginal people. We still need to move into what the whole program is going to be about, those sorts of things, and it gives the community some feeling of power, doesn't it?

Communication between producers and audiences happens in many ways and perhaps most importantly, 'talking about place'. One listener to CAAMA Radio concluded: 'It's Aboriginal radio for Aboriginal people; people who take greater pride in being Aboriginal people, especially grass roots people - it gives them something to listen to and play a part of it'. Another important element that emerged in this commentary is the absence of simplistic representations by indigenous media. Many participants and interviewees felt this was because indigenous people were in control. One listener from Port Augusta in South Australia put it like this:

Oh, it's the aboriginal content; it's them being Aboriginal themselves and there's no stereotyping and stuff like that, it's, you know they're readily accepted and enjoyed and, yeah. I think that, from some of the mainstream radio stations that are [a world] apart because they can get down to the level 
that we want to listen to and what they want to talk about... and certainly the way that they're able to put it across in a way that is, yeah, that is acceptable to us, you know. And the terminology, the everything - they know what they're talking about. We, we can relate to it.

The nature of this relationship was also attributed to the open nature of indigenous radio and television enterprises and, in this case, throughout the islands of the Torres Strait: 'They're very open in their [approach]. If you've got something you want to put on the radio, they call in, you know, talk about your idea. If it's community news or, you know, you go into the studio and do all of that'.

The critical role radio plays in maintaining communication links between prisoners and their families, largely through music requests and associated messages, was commonly raised by audiences across the country. Perhaps this is not surprising with indigenous people making up around 22 per cent of the prison population - and just two per cent of the total population of Australia (Krieg 2006). The continuing high rates of indigenous incarceration and death-in-custody in Australia alone makes this an essential service.

For many, indigenous media is defined in terms of simply feeling comfortable listening to or watching programmes with which they can identify and trust. This Palm Island interviewee reflected the views of many: 'Cherbourg Murri radio is very informative. It presents a point of view that we want to talk about - what you people call the blueprints of your world. We know our blueprints... it concerns the whole world and it gives us a sense of identity and direction'. Audiences around the country identified the wide variety of programming types and styles as a major draw for them, covering music, language, gospel, sporting, multicultural programming, community service announcements, talkback, and news and information - within an indigenous framework, as this Torres Strait Island listener argues:

I think it's more to the point, you know. It's truthful, you know. You get none of that media hype that you hear down south or...there's no rude stuff on the radio. you know...you don't get people who come on the radio and insult people and things like that. People are going to be straight forward; they be 
straight forward and tell the truth, you know - no beating around the bush, which is good, it's good.

One Melbourne listener to the local indigenous community radio station, 3KND [Kool ' $\mathrm{N}$ Deadly] described how she tuned in: 'I heard about 3KND from indigenous friends who I met through work and she, I said to her, "I want to learn more about indigenous culture” and she said, "Listen to the radio station”". Another young, indigenous woman acknowledged that 'pretty much all the elders in Inala [a suburb with a high indigenous population near Brisbane] listen to 98.9', confirming its 'authorisation', like other indigenous stations, by key community figures. This was a common theme around the country: the importance of seeking confirmation from those in the community for whom they have the greatest respect.

\section{Defining the 'electronic message stick'}

Audiences for indigenous media around Australia defined indigenous media in many ways: 'the electronic message stick of the new millennium' was one eloquent response by a caller to the national indigenous talkback program, Talkblack. But there are many other variants: 'our voice’ was a simple description from the Torres Strait, the 'Murri grapevine', or the 'bush telegraph', others. One passionate Palm Islander explained why he listened to indigenous radio: 'Because it's blackfella listening to blackfella. You know you want to communicate with them. You know!'

Indigenous radio and television represent a first level of service in terms of the provision of news and information for indigenous communities. But it is also clear that media organisations do far more than that for communities who feel isolated by persistently negative and irrelevant mainstream media representation. Indigenous audiences undoubtedly consider their local media as an essential service. Some argue that it should be considered alongside other more traditional community services like health and education. The idea that indigenous media provide an essential service is widespread among listeners and viewers. A discussion around this idea at a focus group of listeners to CAAMA Radio in central Australia provoked this pithy response: 'I have to say in that context it's an essential service it just needs perhaps some kind of review into the funding whether its adequate... Why aren’t they putting it into the 
only media that's getting out there?' Two more responses from central Australia underline this theme:

The radio station [at Yuendumu] itself is, I think, the hub of life. In some places it's the school, but here it's the radio station and they make it very, very relevant...And everybody's playing the radio here in every house you go into and the shops, everything! It's on all the time.

The whole media network [PY Media] is absolutely critical to informing people with what's going on in their lives, the future, so that generations can now make a decision about what's best for them. It's the only alternative information they get...people are not functionally literate because of the failure of the education system so that the only real information people get is what they generate themselves through their own organisations.

\section{Managing community resources}

An important role audiences identified as being carried out by indigenous media is in linking individuals and groups within communities. This is especially the case where communities are spread over vast areas, as is the case throughout remote Australia, including the islands of the Torres Strait. The capacity for people to come together for meetings on a regular basis is extremely limited - but innovative uses of media have managed to overcome this in several regions. One is a unique system of broadcast radio, television, and UHF radio devised by PY Media to maintain traditional processes of decision making by consensus in the Anangu-PitjantjatjaraYunkantjatjara (APY) lands in the central desert. As this interviewee - an Anangu elder - explains, whenever the APY Council holds a meeting, people out in the community need to know what's happening:

We need to have meetings, not a secret. They've got to be open, on the table and through radio broadcasting, a lot of people are out there listening. Sometimes, when something really important comes up, they ring the meeting and they talk in the meeting. They're way over there in the community but they can be in the meeting here, talking. 
It is clear from audience responses that in many remote regions, communication through indigenous media such as RIBS (Remote Indigenous Broadcasting Service), formerly known as BRACS (Broadcasting for Remote Aboriginal Communities Scheme), has taken the place of regular community meetings. People in areas like the Torres Strait use the radio network through BRACS to raise and discuss issues such as erosion, disease threat, and local politics. Talkback is a popular format for doing this and is considered to fulfil the role of 'a regional public meeting'. But the use of indigenous radio as a meeting place is not confined to remote Australia, as this comment from the troubled community of Palm Island suggests:

We can talk about these issues rather than having to go house to house or through the Murri Grapevine, as we call it, and, of course, through community meetings which we haven't been able to do recently. Those are sorts of ways of communicating between people. It's all about lifting people's spirits once they know what's happening.

All of this suggests a central organising role for indigenous media outlets. It is clear from this recent extensive fieldwork across Australia, coupled with prior research, that audiences for indigenous radio and television see them as essential services. In locations where it is active, indigenous media plays a central organising role in community life, captured in part by the observations of this Palm Island interviewee:

[Local radio station] 4K1G provided our mob(1) with a balance by getting what we wanted to say on national talkback radio through the Indigenous network...That's why black radio and black media needs to stay around as long as it can because it's the only tool we've got here. It's our vehicle to tell our stories and what's important to us.

This response was indicative of many who see indigenous media as 'theirs'. It is clear from this perception of intimacy that indigenous community radio, in particular, helps audiences to maintain social networks by enabling kinship ties to be strengthened through a range of activities including dance, interviews, stories, prisoners' shows, and by playing music and video requests. This exchange in the remote central desert offers a deeper role for locally produced media for this Anangu man: 
Interviewer: What does it do for young people?

Interviewee: They're learning.

Interviewer: What do they learn about?

Interviewee: Culture, and some inma [dances, songs]. The older people have been dancing before and they're watching and they're learning from that culture...Very important one for children learning...later they singing and some people learning singing and dancing.

As this comment suggests, in the eyes of their audiences, indigenous media are playing a strong educative role in communities, particularly for young people. This was a universal view held by audiences from urban to remote regions. Indigenous media offer audiences an alternative source of news and information which avoids stereotyping. It promotes self-esteem, epitomised in this comment from Central Australia:

Radio is one of the coolest things that they can do and we usually have a queue of our young people wanting to work with Warlpiri Media all out there but particularly on those multimedia projects...we have all the same issues as any other community but we also have extremely strong people, not only elders, now the young people they're taking action and they're not accepting those unacceptable ways of life.

But indigenous-produced media are helping to break down stereotypes about indigenous people for the non-indigenous community, too, thus playing an important role in enabling cross-cultural dialogue. This was evident in earlier research (Forde et al. 2002) and suggests a continuing role for tertiary level journalism programmes around Australia that are linked to local indigenous radio and television producers. This focus group member in Brisbane sums it up:

I would say that another reason I like tuning in, too, particularly to 'Let's Talk’ show [by Tiga Bayles] because it's a credible alternative to mainstream news that it's more balanced and you're given the truth. And as I say, it's out 
there - discrimination and the racism - and there's a lot of things that go on that you just don't get a balanced view in mainstream media.

Audiences identified indigenous radio and television as crucial media for specialist music and dance - without this outlet, it is doubtful if any indigenous-produced music and video would ever be seen or heard on the Australian airwaves. Virtually every indigenous community in the country has at least one local teenage band most have half a dozen or more. Indigenous community radio and television virtually alone support the huge indigenous music industry that remains largely unknown to most of non-indigenous Australia. The role of music - particularly requests - in cementing kinship ties is evident in this response:

[It's] getting to hear your local family, you know, singing as well, which is often not been the case because they never had the opportunities in the past to get their music out there... and that really goes to strengthening family ties...it's a multi-faceted sort of issue because...where people have never, not had the opportunity to talk about their lifestyle or their feelings or anything, you know they can bring them out in their music. And you know it's going to get out into the community and...I think that's a really good way of really empowering Aboriginal people.

\section{Indigenous public spheres}

A critical element of the notion of the public sphere is in the relationship stemming from a shift in the role of the mass media as centres of rational-critical discursive activity to commercialised vehicles for advertising and public relations - all of this within the context of the decline of the liberal public sphere in the 19th century. Habermas (1974: 29) describes the public sphere as 'a realm of our social life in which something approaching public opinion can be formed'. This early model was developed with acknowledgment of a strict separation between the public and private realms of society. But for Habermas, unrestricted access to the public sphere is a defining characteristic with the role of the mass media a central element of the process.

The decline of the liberal public sphere, according to Habermas (1989), was hastened with a shift from the media being a forum for rational-critical debate for private citizens 
assembled to form 'a public', to a privately owned and controlled institution that is easily manipulated by publishers. Despite its flaws and critics, this public sphere model does offer ways of reconceptualising the limits of democracy. For Nancy Fraser, an important theoretical task is to 'render visible the ways in which societal inequality infects formally exclusive existing public spheres and taints discursive interactions with them' (Fraser 1993: 13). So her reconceived public sphere model theorises it as a space where participants with similar cultural backgrounds can engage in discussions about issues and interests important to them, using their own discursive styles - and genres and formulating their positions on various issues. It is then that these are able to be brought to a wider public sphere in which 'members of different more limited publics talk across lines of cultural diversity’ (Fraser 1993: 7).

This assumes the existence and operation of multiple public spheres where members of society who are subordinated or ignored - 'subaltern counter publics' - are able to deliberate among themselves (Fraser 1993: 14). My concern here is with how indigenous people continue to 'make themselves' within their own public spheres and the implications that flow from this. To me, that is how indigenous public spheres must be defined.

It is clear from the commentary from a wide cross-section of audiences for indigenous media that indigenous public spheres should not be understood in terms of a nondominant variant of the broader public sphere. Although they develop in close proximity to - and with a great deal of influence from - mainstream society, they should be seen as discrete formations that exists in a unique context as the product of contestation with the mainstream public sphere. Parallel universes, perhaps. While they operate within a dominant context, it is their 'indigenousness' that is the defining characteristic (Avison 1996). Indigenous public spheres can thus be seen as providing opportunities for people who are regularly subordinated and ignored by mainstream public-sphere processes. They enable indigenous people to deliberate together, to develop their own counter-discourses, and to interpret their own identities and experiences. This highlights the importance of seeing the notion of Aboriginality, or identity formation, as a dynamic process which is facilitated through dialogue (Langton 1993). 
Indigenous public spheres might be defined in various ways: as sites of discursive activity, like meetings and media production; as the process of public opinion formation; and as conceptual ideas, focusing on analysis of the phenomenon of the public sphere (Avison 1996). Indigenous public spheres are frames to be understood as existing on a variety of levels: clan, community/reserve, provincial/territorial, regional, urban, national, and international. They are also constituted, in some ways, by mainstream media. They are sites where indigenous people find the information and resources they need to deliberate on issues of concern to them. In keeping with Habermas's principle of publicity, indigenous public spheres are accessible to all citizens and, ideally, are spaces where the views of participants are judged and authorised, according to existing protocols, rather than relying on the status apportioned to a source by non-indigenous journalism practices. In fact, the very nature of nonindigenous journalistic inquiry is in direct conflict with traditional knowledgemanagement processes in indigenous societies. Storytelling, art, and music - and even silence - are important ways in which people make their positions known, as are the particular ways in which they are presented. An ideal indigenous public sphere accommodates such varied and culturally specific communicative styles. Indigenous public spheres are spaces that can accommodate a wide range of non-mainstream discursive styles and non-traditional perspectives. They are sites where collective selfdetermination can take place. They ideally engage in public dialogue where cultural values, political aspirations, and social concerns of participants are introduced into larger public spheres where they might influence discussions there, hence playing an important role in the broader processes of democracy (Meadows 2001; Avison 1996: $58)$.

Along with the physical size of communities, the values and institutions of oral societies - through practices such as gift exchange and sharing - play a key role in framing public-sphere activity. As with the dynamic notion of identity, the nature of 'traditional' indigenous public spheres has waxed and waned according to the nature and extent of the dialogue with non-indigenous society. It seems evident that many traditional indigenous public spheres went into decline following European contact as a result of communities being marginalised and disenfranchised through their lack of access to information, land, and the control and management of their lives under colonial government. The enforced gathering of indigenous people into settlements and 
missions played an important part in this and has been reflected in mainstream media representations of indigenous people since European invasion in 1788 (Meadows 2001).

However, the evidence from this and previous studies suggests that community broadcasting in Australia - and elsewhere - is challenging the established power base of mainstream media by empowering participants in various ways. It strengthens Rodríguez's (2001: 79) suggestion that we should avoid defining alternative media or in this case, indigenous community broadcasting - in terms of its opposition to mainstream media and rather focus on the 'transformative processes they bring about within their participants and their communities'. This directs our attention to considering the impact of community media within the context of people's everyday lives. Indigenous media is a central element in the representation of culture. The dissemination of different ideas and assumptions about the world and the creation of a space in which to talk about such things affirms a place for millions of Australians, both indigenous and non-indigenous, by validating their 'whole way of life'.

\section{Conclusion}

The importance of understanding the processes of minority media extends well beyond minority media public spheres themselves. Valaskakis (1993), too, is in no doubt of this:

It is through the prism of parallel voices, of competing narratives, expressed in public text - in literature, art, music, ceremony, and media - that we can access the subaltern experience, expand our concepts of inquiry, and approach our points of connectedness.

At the centre of democratic life are the public spheres in which private citizens learn about and comment on issues that concern them. These discursive activities take place in various settings - classrooms, associations, unions, community meetings, and in provincial and national arenas. While most citizens take access to these spaces for granted, a great many 'other' citizens are systematically excluded. The advent of mass democracy and mass media has seen the concept of the 'imagined community' (Anderson 1984) - the nation - become societies of multiple-connected public spheres. 
The continuing circulation of ideas and assumptions about the indigenous world, through indigenous media, contributes to the development of a national indigenous public sphere by highlighting common experiences and issues. But importantly, indigenous media also acts - most often quite deliberately - as a cultural bridge between the parallel universes of indigenous and non-indigenous society. They provide sites for public opinion formation; sites where citizens can engage in collective efforts to bring their issues to the dominant public sphere; and sites where indigenous people can attempt to influence the policies of various governments through the pressure of public opinion. Indigenous media represent important cultural resources which provide their respective communities with a first level of service. And it is indigenous media, globally, that continue to play a central role in offering a critique of mainstream media and its place in the formation of the broad democratic public sphere.

The Australian indigenous broadcasting sector is providing an essential service for a diverse range of communities across the country. It is much more than simply a purveyor of news, information, and music, although it is the only source of relevant information for these. Indigenous media enterprises are inexorably part of indigenous cultures, reflecting the 'real world' of their past, the present, and future - electronic Dreaming tracks. By their very nature, they fulfil multiple roles within their communities - unique, complex roles that are simply beyond the capacity or will of existing mainstream organisations.

\section{Acknowledgments}

The project on which this article is based was conducted by the author with Griffith University colleagues Susan Forde, Jacqui Ewart, Kerrie Foxwell, and senior indigenous researcher Derek Flucker. It was funded jointly by the Australian Research Council, the Community Broadcasting Foundation, and the federal Department of Communication, Information Technology and the Arts.

\section{Note}

1. The colloquial term 'mob' is one commonly used by Australian indigenous people to refer to a group of individuals. 


\section{References}

Anderson, Benedict (1984) Imagined Communities: Reflections on the Origin and Spread of Nationalism, London: Verso.

Australian National Parks and Wildlife Service and the Mutitjulu Community (1990) An Insight into Uluru: The Mala Walk and The Mutitjulu Walk [information booklet], Canberra: Australian National Parks and Wildlife Service and the Mutitjulu Community.

Avison, Shannon (1996) 'Aboriginal Newspapers: Their Contribution to the Emergence of an Alternative Public Sphere in Canada', unpublished MA Thesis, Montreal: Department of Communication Studies, Concordia University.

Avison, Shannon and Michael Meadows (2000) 'Speaking and hearing: Aboriginal newspapers and the public sphere in Canada and Australia', Canadian Journal of Communication 25(3): 347-366.

Forde, Susan, Michael Meadows, and Kerrie Foxwell (2002) Culture, Commitment, Community: The Australian Community Radio Sector, Brisbane: Griffith University. Fraser, Nancy (1993) 'Rethinking the Public Sphere: A Contribution to the Critique of Actually Existing Democracy', in B. Robbins (ed.) The Phantom Public Sphere, Minneapolis: University of Minnesota Press.

Habermas, Jurgen (1974) 'The public sphere: an encyclopedia article’, New German Critique 3: 29-35.

Habermas, Jurgen (1989) The Structural Transformation of the Public Sphere: An Inquiry into a Category of Bourgeois Society, Cambridge MA: MIT Press.

Krieg, Anthea S. (2006) 'Aboriginal Incarceration: Health and Social Impacts', available at http://www.mja.com.au/public/issues/184_10_150506/kri10234_fm.html (retrieved 21 January 2008).

Langton, Marcia (1993) “"Well, I heard it on the radio and I saw it on the television”: An essay for the Australian Film Commission on the politics and aesthetics of filmmaking by and about Aboriginal people and things’, Sydney: Australian Film Commission.

Meadows, Michael (2001) Voices in the Wilderness: Indigenous Australians and the News Media, Westport: Greenwood Publishing.

Meadows, Michael; Forde, Susan; Ewart, Jacqui and Foxwell, Kerrie (2008)

Community Media Matters: an audience study of the Australian community broadcasting sector, Brisbane: Griffith University. 
Michaels, Eric (1986) Aboriginal Invention of Television Central Australia 19821985, Canberra: Australian Institute of Aboriginal Studies.

Molnar, Helen and Michael Meadows (2001) Songlines to Satellites: Indigenous Communication in Australia, the South Pacific and Canada, Leichhardt: Pluto Press. Rodríguez, Clemencia (2001) Fissures in the Mediascape: An International Study of Citizens’ Media, Creskill, NJ: Hampton Press.

Valaskakis, Gail (1993) 'Parallel Voices: Indians and Others - Narratives of Cultural Struggle', Canadian Journal of Communication 18(3), available at http://www.cjconline.ca/viewarticle.php?id=179\&layout=html (retrieved 21 January 2008).

\section{The author}

Michael Meadows is Associate Professor of Journalism in the School of Arts at Griffith University in Brisbane. He worked as a journalist for 10 years before moving into journalism education in the late 1980s. Since then his research interests have included Indigenous and community media, journalism practices, and the media representation of Indigenous affairs. Contact details: School of Arts, Griffith University, Nathan, QLD 4111, Australia.>m.meadows@griffith.edu.au> 